UCRL-JC-128689

PREPRINT

\title{
The National Ignition Facility for Inertial Confinement Fusion
}

\author{
J. A. Paisner \\ J. R. Murray
}

This paper was prepared for submittal to the 17th IEEE/NPSS Symposium on Fusion Engineering San Diego, CA

October 6-10, 1997

October 8, 1997

This is a preprint of a paper intended for publication in a journal or proceedings. Since changes may be made before publication, this preprint is made available with the understanding that it will not be cited or reproduced without the permission of the author. 


\section{DISCLAIMER}

This document was prepared as an account of work sponsored by an agency of the United States Government. Neither the United States Government nor the University of California nor any of their employees, makes any warranty, express or implied, or assumes any legal liability or responsibility for the accuracy, completeness, or usefulness of any information, apparatus, product, or process

disclosed, or represents that its use would not infringe privately owned rights. Reference herein to any specific commercial product, process, or service by trade name, trademark, manufacturer, or otherwise, does not necessarily constitute or imply its endorsement, recommendation, or favoring by the United States Government or the University of California. The views and opinions of authors expressed herein do not necessarily state or reflect those of the United States Government or the University of California, and shall not be used for advertising or product endorsement purposes. 


\title{
The National Ignition Facility for Inertial Confinement Fusion*
}

\author{
J. A. Paisner and J. R. Murray \\ University of California \\ Lawrence Livermore National Laboratory \\ P. O. Box 808, Livermore, CA 94551
}

\begin{abstract}
The National Ignition Facility for inertial confinement fusion will contain a $1.8 \mathrm{MJ}, 500 \mathrm{TW}$ frequencytripled neodymium glass laser system that will be used to explore fusion ignition and other problems in the physics of high temperature and density. We describe the facility briefly. The NIF is scheduled to be completed in 2003.
\end{abstract}

\section{INTRODUCTION}

The United States Department of Energy has established a project to construct a National Ignition Facility (NIF) for inertial-confinement fusion (ICF) and other research into the physics of high temperatures and high densities. The facility will contain a neodymium-glass laser capable of irradiating targets at an energy of $1.8 \mathrm{MJ}$ and peak power of $500 \mathrm{TW}$ at the third harmonic ( $351 \mathrm{~nm}$ wavelength) in a pulse shape suitable for an ICF ignition target. A recent review by Lindl [1] discusses the target physics of ICF indirect-drive targets and the prospects for fusion ignition and propagating burn with a laser driver of this sort. The NIF will also allow directdrive illumination of fusion targets, and will be used for a wide variety of other experiments in nuclear weapons physics, weapons effects studies, and laboratory astrophysics. Perry and Remington [2] recently described some of the wide variety of weapons physics experiments that have been conducted on the Nova laser at LLNL and that will be continued and expanded using NIF.

Figure 1 shows an overall view of the facility, which has two laser bays extending to the left of the figure and a cylindrical concrete target chamber building between two beam switchyards at the right front. The NIF laser and target area building will occupy an area of about $125 \times 170 \mathrm{~m}^{2}$.



Fig. 1. Overall view of the NIF laser and target area building.

* Research supported by the U. S. Department of Energy under contract W-7405-ENG-48 by the Lawrence Livermore National Laboratory. 


\section{THE NIF LASER SYSTEM}

\section{A. General features}

The NIF laser system will have more than an order of magnitude higher power and energy than the largest fusion laser systems now operating. As a consequence, it is very important to minimize construction and operating costs for the system. NIF tangets will typically be larger than targets used with smaller lasers, which leads to somewhat longer pulses. A laser design that uses only a single, large power amplifier stage with multiple passes through that stage has both many fewer components and better saturation properties for long pulses than typical single-pass laser designs [3], so we have chosen a multipass design with a single size of Brewsterangle laser slabs for NIF. The amplifier is split into two sections separated by a vacuum spatial filter to improve its performance for short, high-peak-power pulses.

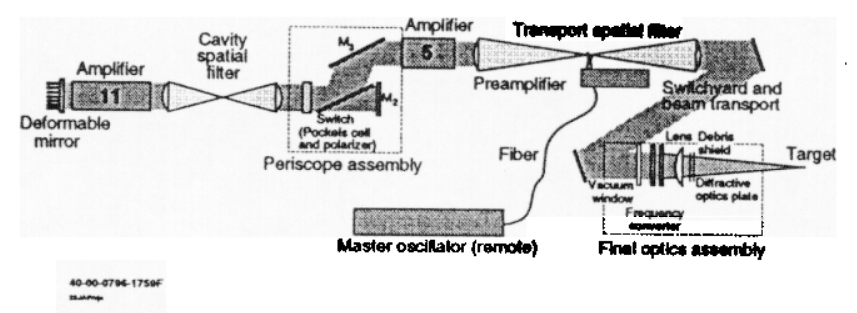

Fig. 2. Schematic layout of the NIF laser system.

Figure 2 is a schematic layout of the major components of the NIF laser. A preamplifier module amplifies and spatially shapes a pulse from the master oscillator, and injects this pulse into the laser near the focal plane of a transport spatial filter. The spatial filter recollimates the beam at full size, and it then passes through a 5-slab-long power amplifier and reflects from a thin-film polarizer to enter the main laser cavity. After passing through the cavity spatial filter, it is amplified by an 11-slab-long main amplifier, strikes a deformable mirror, and returns through the main amplifier and cavity spatial filter. By the time it reaches the other end of the cavity spatial filter, the Pockels cell has been fired to rotate the polarization so the pulse passes through the polarizer and reflects back from a cavity end mirror. It makes another double pass through the cavity spatial filter and main amplifier and returns to the Pockels cell, which has now switched off so that the pulse reflects from the polarizer. The pulse passes back through the transport spatial filter at a slight angle to its initial path, missing the injection mirror, and reflects from a series of mirrors that direct it to the target chamber. Here it passes through frequency conversion crystals and a lens that focuses it onto the target.

The largest practical size for laser glass slabs and nonlinear crystals with current technology is a clear aperture of about $40 \mathrm{~cm}$. We have chosen an amplifier aperture size of
$40 \times 40 \mathrm{~cm}^{2}$ for NIF, giving a beam size of slightly less than $38 \times 38 \mathrm{~cm}^{2}$. The NIF will contain 192 of these beams, each separately aligned and pointed to the target using a computer-controlled, automatic alignment system. This system also uses the deformable mirror and a Hartmann sensor on each beam to control the wavefront at the output of the laser.

The basic NIF structural unit is a bundle of beams stacked four high and two wide. Six bundles are close packed to form a cluster of 48 beams, and each of two laser bays contains two clusters. In the switchyard and target area, each bundle of beams is split into two groups of four that are routed to the top and bottom hemispheres of the target chamber. Any combination of beam bundles can be fired independently (though all beams in an active bundle must be fired).

A prototype of a single beam of the NIF system (at a slightly smaller beam size of $35 \times 35 \mathrm{~cm}^{2}$ ) called "Beamlet" was completed in 1994 at LLNL. Operation of this prototype over several years has demonstrated that the NIF design parameters can be realized in a large system [3].

\section{B. Clean assembly and maintenance strategy}

Particles and other residues in large laser systems can explode and lead to damage to optical components when exposed to high fluence laser pulses, so it is extremely important to minimize contamination. It is prohibitively expensive to establish conditions clean enough to avoid dangerous contamination in a large laser bay. For NIF, we shall assemble clean components in a cleanroom and seal these "line-replaceable units" (LRU) in closed, clean containers for transport to the dirty laser bay. These LRU's will then be inserted cleanly into the clean laser structure from their transport containers, where they will engage kinematic mounts that locate them precisely in the desired position. This strategy is similar to the wafer-handling strategy used in modem semiconductor plants, and was derived from that strategy. Most LRU's in the laser are a stack of laser components four high and one wide. Also most of the LRU's will be inserted from the bottom of the structure so that gravity aids in minimizing particulate contamination, though mechanical limitations force some insertions to depart from the bottom-loading strategy.

\section{The NIF laser and target anea building}

The NIF building is based on a stable, reinforced concrete foundation slab that extends under the laser bays and target building. Laser components are mounted on steel and concrete structures in the laser bays, and beam transport mirrors are mounted on a steel switchyard spaceframe on the sides of the target area building. The target area building is a vertical concrete cylinder for stability and radiation shielding. Final laser beam transport mirrors mount to the concrete structure of the target area building. 
The NIF master oscillator and pulse shaping system is based on the fiber optic technology used in high-speed fiber communications networks. The master oscillator is an ytterbium-doped fiber ring oscillator that is directed into a fiber amplifier and splitter array to form 48 separate fiber outputs that can be individually modulated under computer control. Each of these signals is phase modulated to a bandwidth of $30 \mathrm{GHz}$ ( $90 \mathrm{GHz}$ at the third harmonic) to suppress transverse stimulated Brillouin scattering in the lange, high-fluence laser optics at the output of the laser. Phase modulation for beam smoothing by spectral dispersion (SSD) [4] is also applied here, if desired. Each of the 48 outputs goes through an integrated-optics amplitude modulator where its temporal shape can be set to high precision.

Each of the $\mathbf{4 8}$ fiber outputs from the master oscillator room goes to a preamplifier module located in the laser bay underneath the transport spatial filter. The preamplifier module contains a diode-pumped, single-mode glass regenerative amplifier that amplifies the pulse to $\sim 10 \mathrm{~mJ}$, followed by a spatial beam shaper and a flashlamp-pumped, four-pass 5-cm rod amplifier that amplifies the pulse to several Joules (up to $25 \mathrm{~J}$ ). The preamplifier module is an LRU assembled and tested off-line, then installed as a unit. The output from the preamplifier is sampled by a main laser input sensor and is then split into four pulses for injection into a group of four NIF beams.

The NIF amplifiers are particularly important, since they contain roughly half of the full aperture, expensive optical components in the laser. The amplifiers are arranged as two stacks of four beam apertures in a common frame. As shown in Figure 3, laser slab and flashlamp LRU's slide into the frame from below for assembly and maintenance. Figure 4

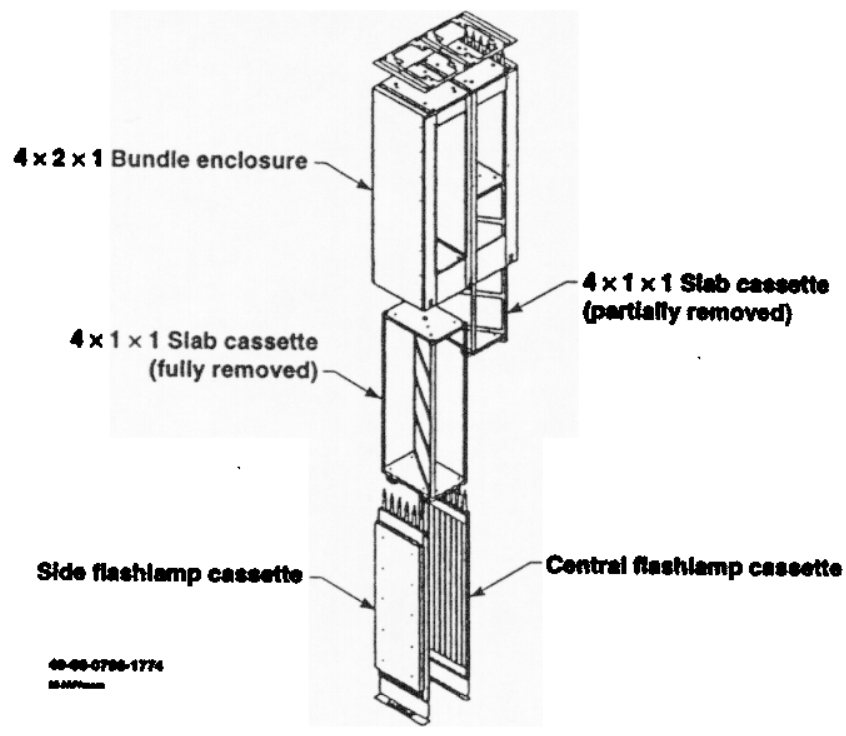

Fig. 3. The NIF laser amplifier is constructed of several easilyreplaceable cassettes. shows an amplifier slab LRU being installed in a prototype of the NIF amplifier in a development laboratory, and Figure 5 shows a photograph of a NIF-sized xenon flashlamp that has been tested to 39,000 shots as part of vendor qualification for the lamps. Figure 6 shows two clusters of NIF

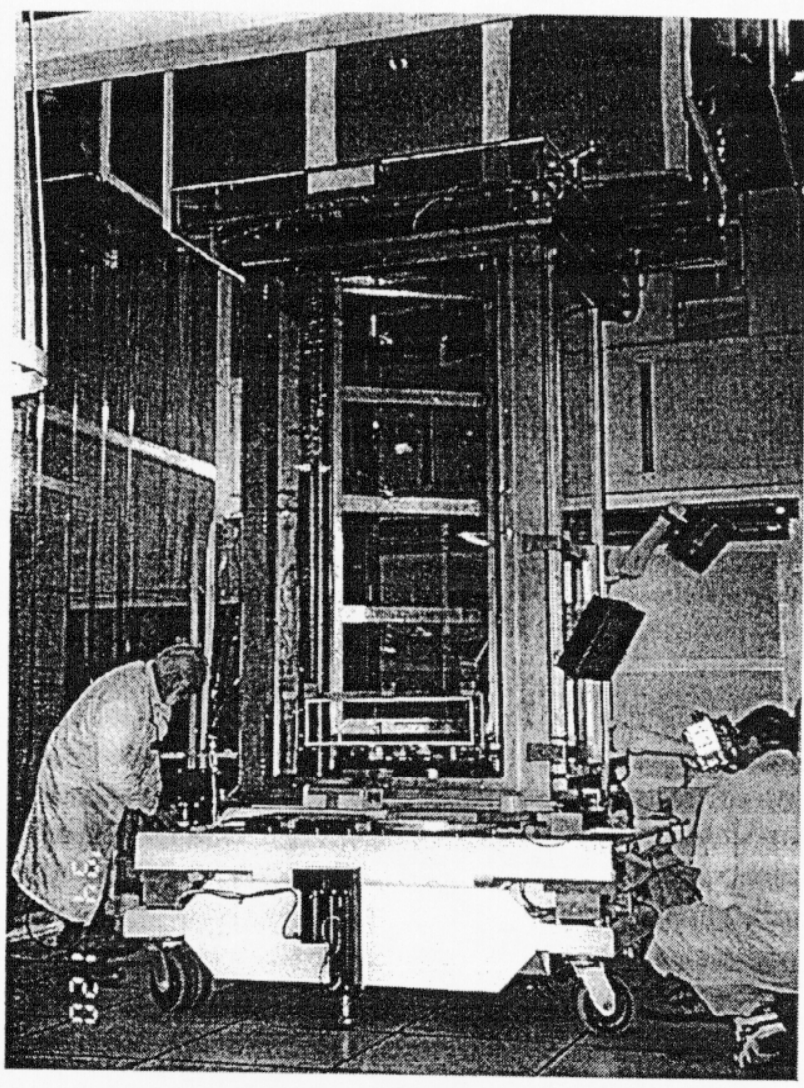

Fig. 4. Transporter inserting a clean column of four laser slabs into the NIF amplifier prototype.

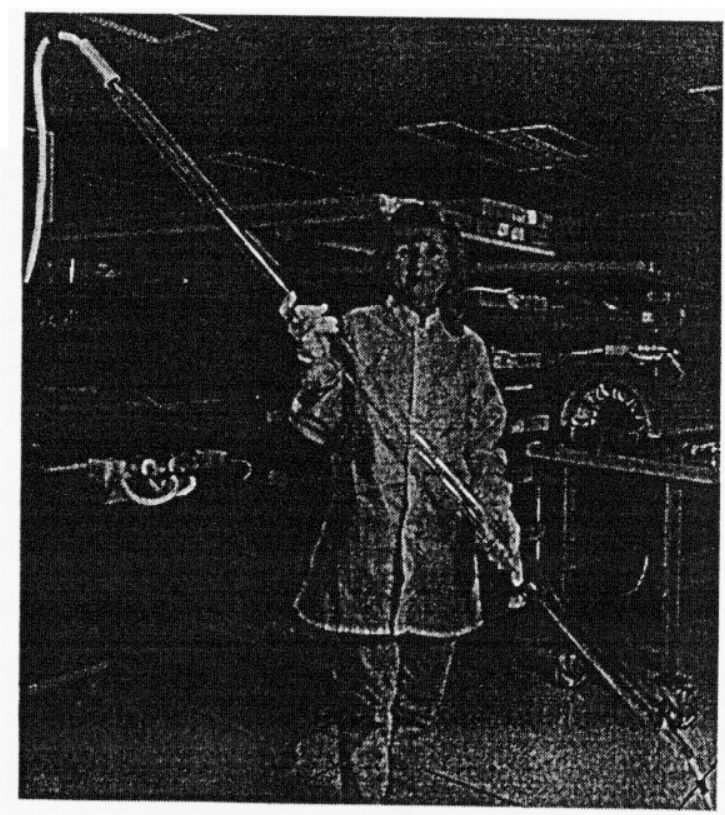

Fig. 5. NIF flashiamp 
amplifiers installed in the laser bay, with access from below for maintenance and from above for utilities such as clean nitrogen gas and pulsed-power cabling.

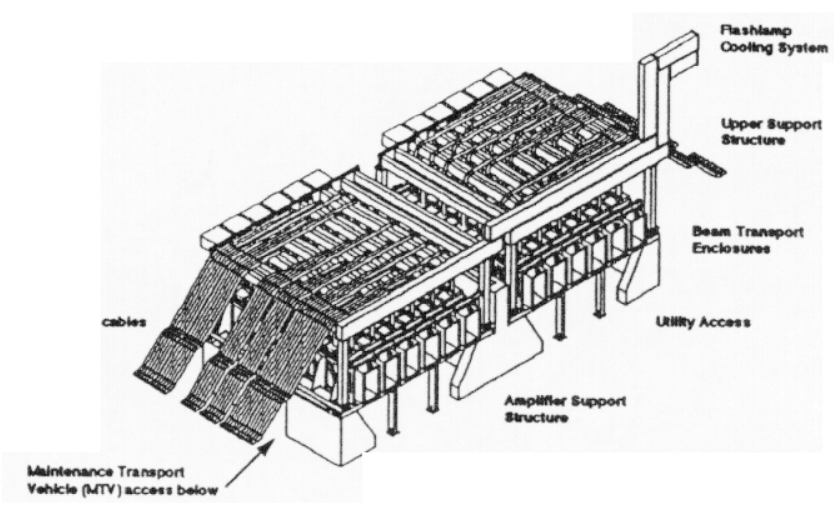

Fig. 6. Each laser bay contains two clusters of six bundles of amplifiers with utilities from above and maintenance from below.

The NIF deformable mirror will have 39 actuators in a triangular grid and a maximum correction range of $\sim 15$ waves. Two commercial vendors are supplying prototypes, and an LLNL design is also available and has been tested on Beamlet.

The NIF plasma-electrode Pockels cell (PEPC) provides gain isolation, switching in the laser cavity as described above, and isolation against stray reflections in the laser system [5]. Thin helium plasmas on both faces of a thin potassium dihydrogen phosphate (KDP) crystal are used as electrodes to charge the surface of the crystal plate and apply an electric field in the direction of beam propagation. The basic PEPC electrical subassembly switches two beams of the laser, as shown in Figure 7. Two of these subassemblies are

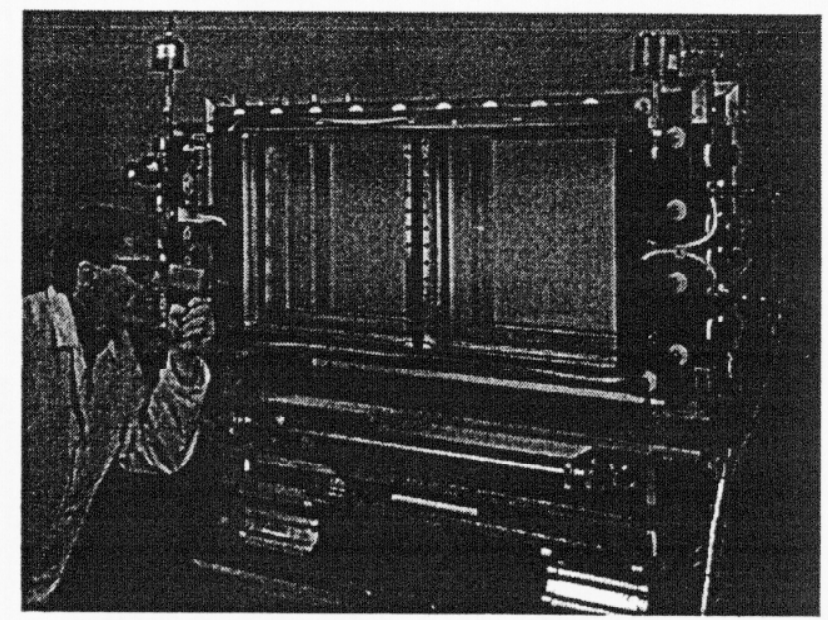

Fig. 7. The NIF Pockels cell is based on a two-aperture building block in an anodized aluminum housing. grouped to form a four-high LRU. This Pockels cell LRU is mounted together with polarizer and mirror LRU's in a structure called the periscope, as seen in Figure 8.

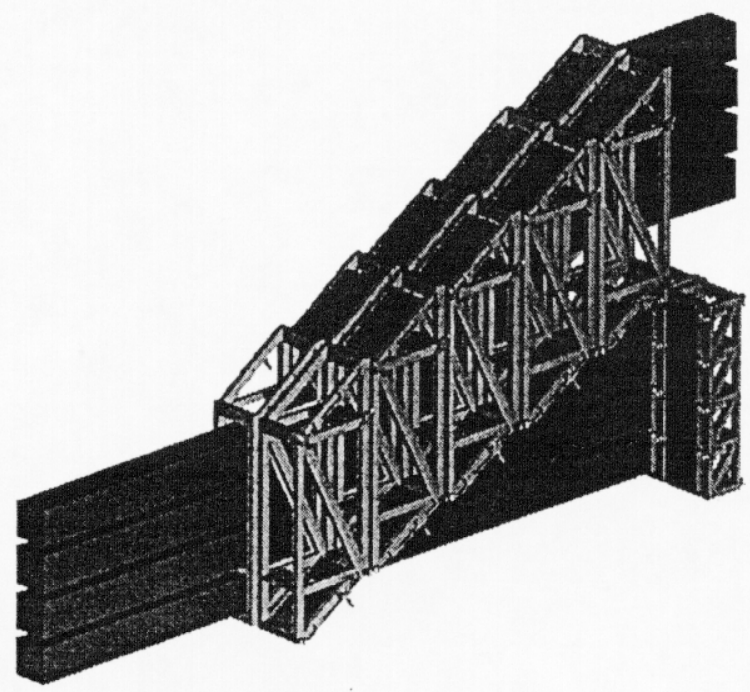

Fig. 8. Pockels cells, polarizers, and mirrors mount in a structure called the "periscope."

NIF uses image-relayed propagation to maintain a uniform intensity profile across the beam and to control the growth of intensity noise. This causes the NIF transport spatial filter to be quite long $(60 \mathrm{~m})$ in order to relay the image properly to the final optics assembly over the long propagation path through the switchyard to the target chamber.

The Final Optics Assembly (FOA) is mounted on the target chamber, as shown in Figure 9. The beam passes through

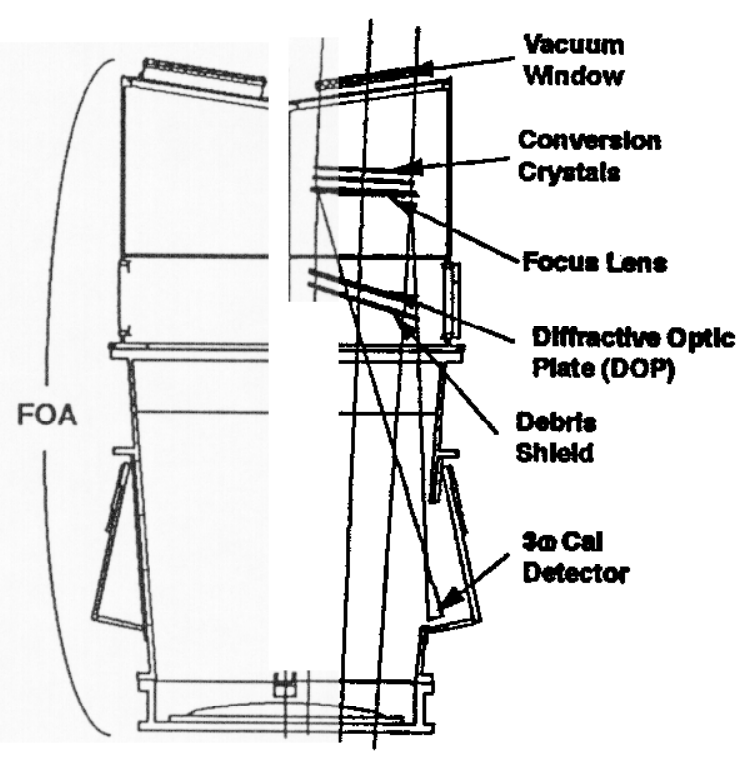

Fig. 9. The Final Optics Assembly mounts on the target chamber. 
a vacuum window before it encounters the frequency converter. This design was chosen because it allows a more robust vacuum window since the laser damage threshold is higher and noise growth due to the nonlinear index of refraction is lower at the one-micron fundamental wavelength than at the 351-nm third harmonic. The frequency converter consists of a thin plate of KDP that converts two-thirds of the input light to the second harmonic, followed by a deuterated KDP mixer that sums the second harmonic and fundamental to give the third harmonic. Beamlet tests have confirmed that whole-beam conversion efficiencies of up to $80 \%$ to the third harmonic can be achieved with high-quality KDP crystals [3].

After frequency conversion, the beam passes through a final focus lens that brings the beam to focus at the center of the target chamber. Past the lens, there is a removable cassette that contains diffractive optical elements including a sampling grating for beam diagnostics, a color-separation grating that deflects light at the fundamental and secondharmonic wavelengths away from the target, and can include kinoform elements to smooth the focal spot distribution or deflect the beam to other locations in the target chamber if desired. Target irradiation at the fundamental and second harmonic wavelengths is also possible with customized diffractive elements in this location. The final element is a fused silica debris shield that protects the other components in the FOA from target debris and tritium contamination.

The line-replaceable unit in the FOA is a single-beam package that extends from a removable cover over the vacuum window to the debris shield. Four of these units are grouped to form a single FOA.

\section{TARGET CHAMBER AND DIAGNOSTICS}

Indirect-drive laser targets commonly use cones of beams entering the two ends of a cylindrical hohlraum [1]. Implosion symmetry is adjusted by manipulating the pulse shapes on these different beams. In the NIF target chamber, the axis of the cylinder will be oriented vertically and the target illuminated by two cones of beams from above and two from below, as shown in Figure 10. The outer cone of beams in

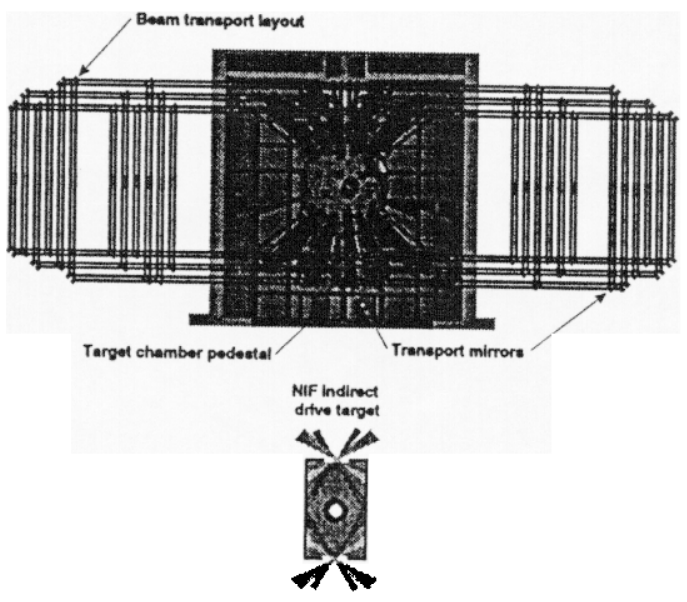

Fig. 10. The NIF indirect drive configuration has two cones of beams from above and two from below. each hemisphere contains 16 FOA's (64 beams), and the inner cone contains 8 FOA's (32 beams). The FOA's and beam transport mirrors are designed so that 24 FOA's can be moved to positions around the waist of the chamber to give spherically-symmetric illumination for direct-drive laser targets, as shown in Figure 11.

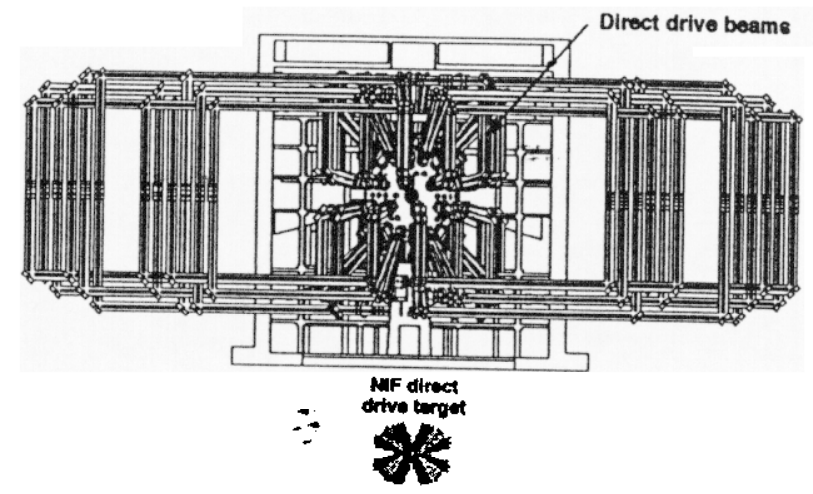

Fig. 11. For direct drive, 24 beams are moved to positions around the waist of the target chamber.

The first wall on the inside of the target chamber will see $\mathrm{X}$-ray and laser fluences up to several $\mathrm{J} / \mathrm{cm}^{2}$. The chamber will be lined with removable aluminum panels coated with plasma-sprayed boron carbide $\left(B_{4} C\right)$, which is highly resistant to $\mathrm{X}$-ray and laser damage. The tips of diagnostic instruments and target positioners will see much higher fluences, and will be designed to be easily replaceable and to minimize damage and shrapnel.

A wide variety of target diagnostic instruments will be used to study the behavior of ignition and other targets. Most of these are not part of the NIF project itself, but will be constructed and installed by the various experimenters who use the facility. The chamber will have 86 ports for mounting these instruments, ranging in size from 15 to $70 \mathrm{~cm}$. There is also a large $(1.7 \mathrm{~m})$ side port for inserting large test assemblies into the chamber.

Access to the chamber for cleaning, replacing wall panels, and the like will be by way of a hydraulic lift that rises through a 1.9-m port at the bottom of the chamber in the center of its support pedestal. The chamber is further supported by the reinforced concrete floors of the target diagnostics experimental areas around its circumference.

\section{OPTICS}

NIF will require about $750040-80 \mathrm{~cm}$ high-quality optical components to be produced over a period of about four years. This greatly exceeds current production capacity, so the NIF project has already begun development projects with large optics vendors to put in place the technology and facilities for this production. Schott Glass Technologies and the Hoya Corporation are developing technology for the continuous melting and pour of neodymium-doped phosphate laser glass. LLNL has developed a fast-growth process for 
KDP and deuterated KDP crystals which has demonstrated growth at $1-2 \mathrm{~cm}$ per day up to a size of $57 \times 57 \times 47 \mathrm{~cm}^{3}$, which is large enough for NIF plates: this process will be transferred to industry for NIF production. Finishing facilities for flat components and lenses are under construction, and development contracts are in place to improve finishing processes and technology.

\section{PROJECT SCHEDULE}

Site excavation and construction of the NIF facility began in July, 1997. We expect to have the building finished to a state that we can begin to install laser components in one laser bay by late 1999 . By September 2001 , one laser bundle ( 8 beams) will be completed and tested through to target chamber center, and early target experiments can begin. In September 2002 , one full cluster ( 48 beams) will be available for target experiments, and activation of a second cluster will be underway. The project will end in September 2003 with two clusters available for target experiments the other two clusters fully installed and in the process of activation.

\section{PROJECT PARTICIPANTS}

NIF is a national project with participation from a number of US laboratories, as well as significant international participation. The project will be located at Lawrence Livermore National Laboratory, which is playing the lead role in the design; however many subsystems and components will be designed or provided by other participants. Los Alamos National Laboratory (LANL) is designing some parts of the laser support structure, manipulators for servicing the target chamber, and many of the target diagnostic instruments. LANL will also play a very important role in NIF ICF and weapons physics target planning and design. Sandia National Laboratory (SNL) is providing construction management for the facility, designing the target chamber and electrical pulsed-power system, and providing installation alignment for the laser and target chamber support structures. The University of Rochester Laboratory for Laser Energetics is providing valuable expertise in optical component development and handling.

The Commissariat á l'Energie A tomique (CEA) of France has been a full partner in the development of laser components for NIF: indeed, many of the parts being assembled in Figure 4 were manufactured in France and sent to LLNL for assembly and test. CEA researchers are presently constructing a single 8-beam bundle called Line d'Integration des Lasers (LIL) at their research facility in Bordeaux, to be available for target experiments in 2002 . They plan to follow this with a 240-beam Laser Megajoule (LMJ). These facilities will use the same basic components as NIF, but will explore some alternative options for laser and final optics architecture. The CEA Phebus laser facility is also being used to develop strategies for protecting the tips of diagnostic instruments and other target chamber components. The Atomic Weapons Establishment of the United Kingdom is design- ing the diagnostic manipulators for the NIF target chamber, and will participate in NIF experiments. AWE is also considering the construction of a laser facility using NIF technology, but somewhat smaller. The Vavilov State Optical Institute in Russia will be supplying some highly-specialized laser diagnostic components. Further national and international collaborations are likely as the project progresses towards completion.

\section{REFERENCES}

[1] J. Lindl, "Development of the indirect-drive uppronch to inertial confinement fusion and the turget physics basis for ignition and gain," Phys. Plasmas, vol. 2, pp. 3933-4024, 1995.

[2] T. Perry and B. Remington, "Nova laser experiments and stockpile stewardship," Science and Technology Review, September 1997, pp. 4-13. Available on the internet at URL htt://www.llal.gov/str/09.97.html

[3] B. M. Van Wonterghem, J. R. Murray, J. H. Campbell, D. R. Speck, C. E. Barker, I. C. Smith, D. F. Browning, and W. C. Behrendt, "Performance of a prototype for a lange-aperture multipass Nd:glass laser for inertial confinement fusion," Appl. Opt., vol. 36, pp. 4932-4953, 1997.

[4] S. Skupsky, R. W. Short, T. Kessler, R. S. Craxton, S. Letaring, and J. M. Soures, "Improved laser-beam uniformity using the angular dispersion of frequency-modulated light," J. Appl. Phys., vol. 66, pp. 3456$3462,1989$.

[5] M. A. Rhodes, B. Woods, J. J. DeYoreo, D. Roberts, and L. J. Atherton, "Performance of large-aperture optical switches for high-energy ICF lasers," Appl. Opt., vol. 34, pp. 5313-5330, 1995. 


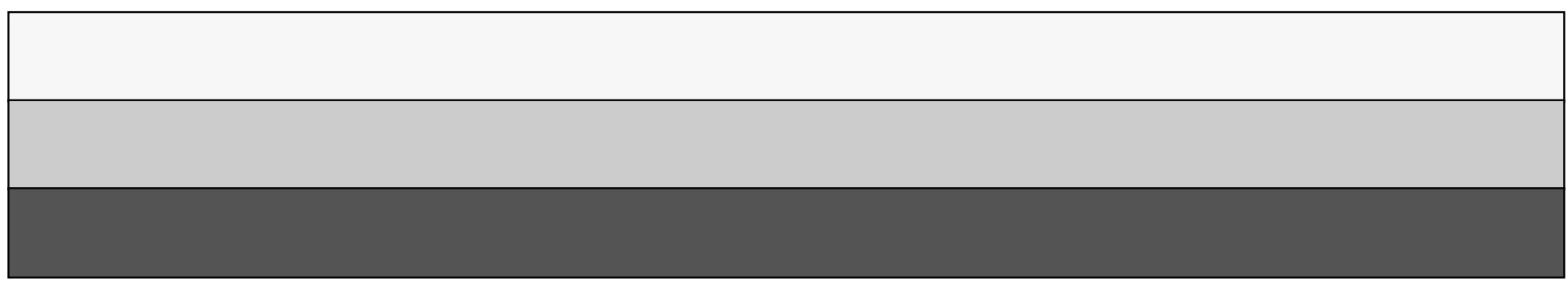

